\title{
Перкутанна латерална остеотомия
}

\author{
Пл. Недев \\ Клиника по УНГ-болести при МБАЛ "Св. Марина" - Варна \\ Катедра по неврохирургия, оториноларингология и офталмология \\ при Медицински университет "Проф. д-р П. Стоянов" - Варна
}

\begin{abstract}
Classically, a combination of lateral osteotomies or/and fractures were used to close the roof that followed radical hump removal. This paper presents our experience in rhinoplastic procedures, combined with percutaneous lateral osteotomies. In conclusion we discuss its efficiency, the possibilities to non-traumatic accomplishment and easy performance.

Keywords: Rhinoseptoplasty, osteotomies, percutaneous lateral osteotomy
\end{abstract}

\section{Резюме}

Класически комбинацията от латерални остеотомии и/или фрактури се използва за затваряне на отворения носен гръб след неговото отстраняване при медиална остеотомия. В статията е представен нашият опит при провеждането на ринопластични процедури в комбинация с перкутанни латерални остеотомии. В заключение се дискутира тяхната ефективност, атравматичност и лекота на изпълнение.

Ключови думи: риносептопластика, остеотомии, перкутанна латерална остеотомия.

\section{Увод}

Риносептопластиката е хирургична интервенция, целяща външна корекция на носа, съобразена с функцията на носната кухина. Важна част от оперативните процедури са провеждането на остеотоми и или фрактуриране на костно-хрущялния гръб на външния нос. След медиална остеотомия носният гръб остава „отворен” и придобива трапецовидна форма. Това налага предприемането на латерални остеотомии с цел стеснение и прибиране гърба на носа. Разбира се, при тесни носове и ред други обстоятелства необходимостта от латерална остеотомия може и да отпадне (Деспотов 2002).

\section{Материал и методи}

Перкутанна латерална остеотомия сме използвали при 278 пациенти - $187(67,2 \%)$ жени и при $91(32,8 \%)$ мъже.

Перкутанната латерална остеотомия извършваме по следния начин и в следната последователност:

1. Рутинно протичане на ринопластичните етапи и процедури. Медиална остеотомия за отстраняване на носния гръб.

2. Ендоназално предприемаме медиална коса или парамедиална остеотомия.

3. Със скалпел № 15 се провежда кожна инцизия (чрез бодване и достигане до костните структури на острието. Разрезьт е достатъчно мальк и фин, за да не остане видим белег след операцията. В същото време той е толкова голям, че през него трябва безпрепятствено на влезе тьнкото 2 мм длето. 
4. Длетото се поставя и след като се убедим палпаторно, че е достигнало костта, се провеждат дозирани удари с чук.

5. Ударите с чук се провеждат нагоре до освобождаване на фрактурирания сегмент, както и до долу - aperture pyriformis.

6. При положение, че след приключване на остеотомията костта не е мобилна, с помоцта на луер или чрез дигитално притискане се постига фрактуриране на желания костен фрагмент и мануалното му моделиране.

7. Фиксационна превръзка.

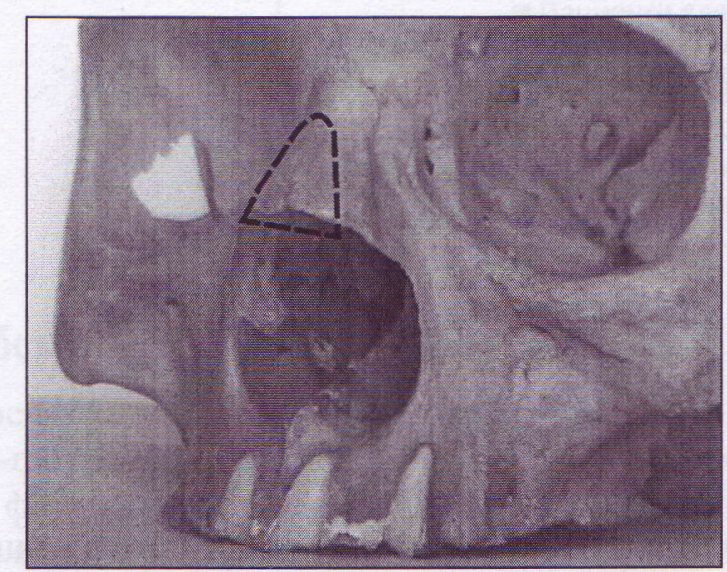

Фиг 1. Медиална остеотомия

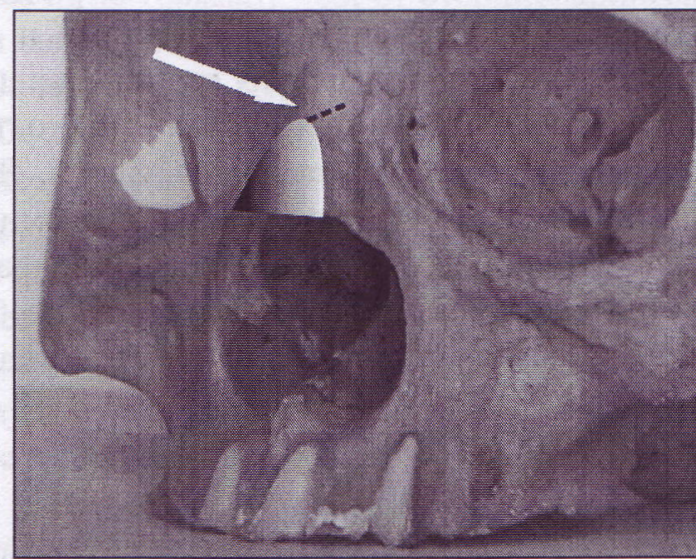

Фиг. 2. Медиална коса остеотомия

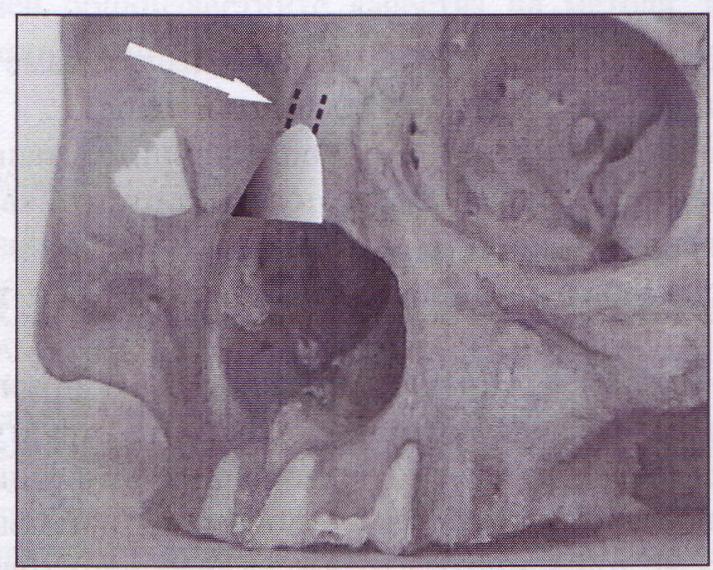

Фиг. 3. Парамедианни остеотомии

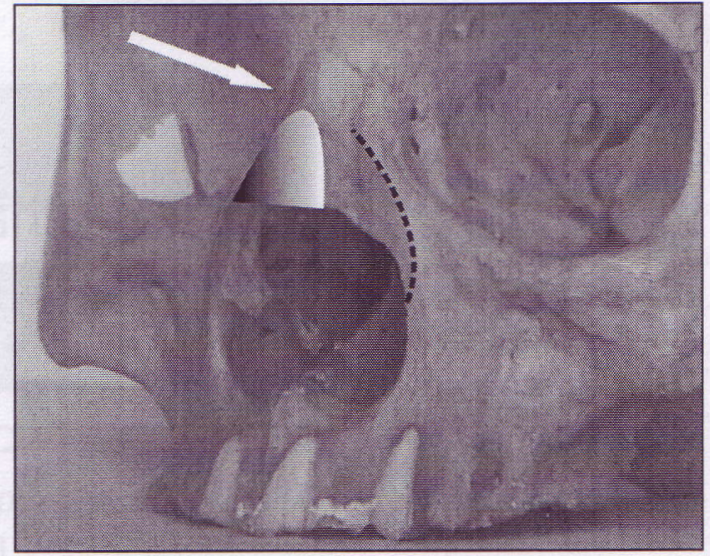

Фиг. 4. Долно - възходяща латерална остеотомия

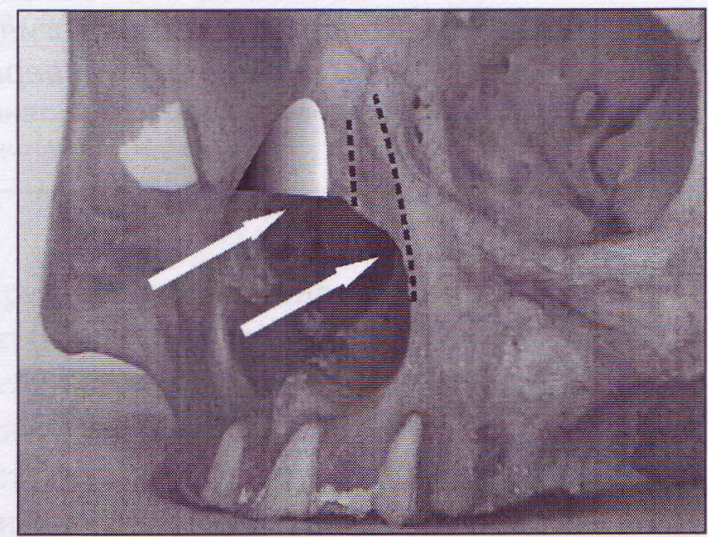

Фиг. 5. Двойна латерална остеотомия

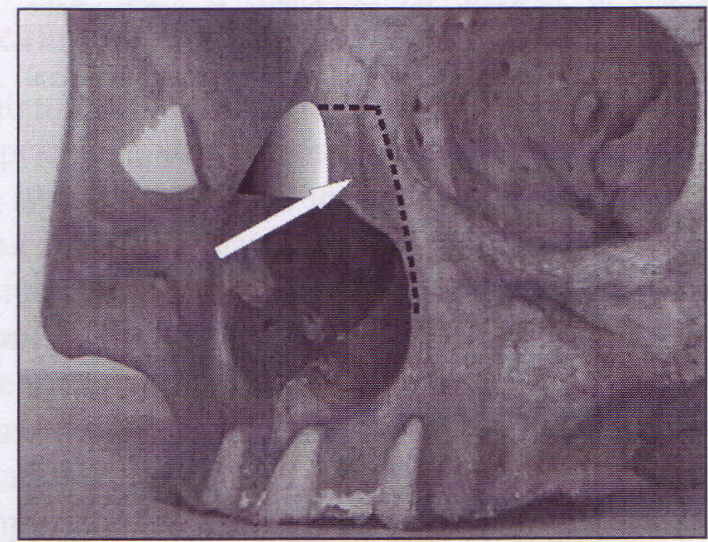

Фиг. 6. Комбинирана остеотомия

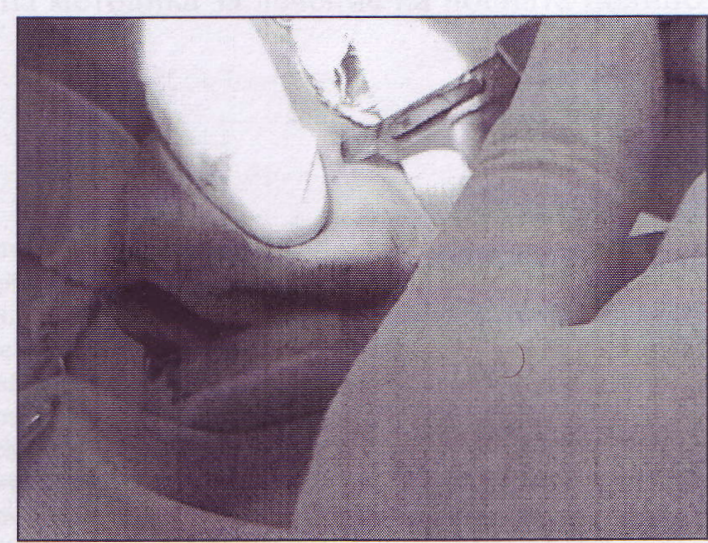

Фиг. 7. Кожна инцизия със скалпел № 15 


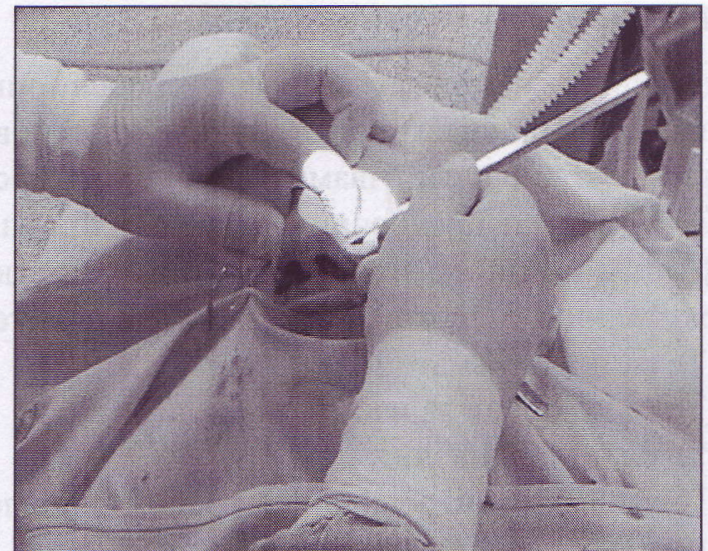

Фиг. 8. Перкутанна остеотомия вляво

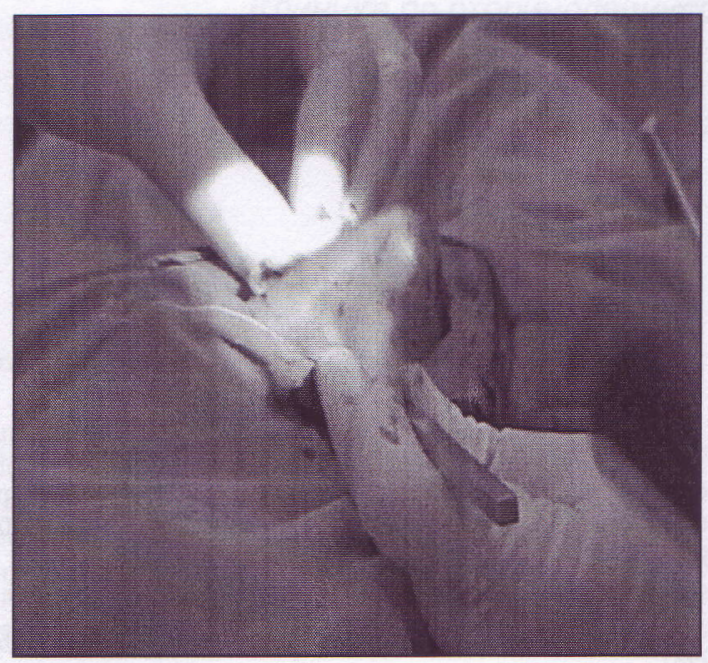

Фиг. 9. Перкутанна остеотомия вдясно

\section{Резултати и обсъждане}

Кифектомия (премахване на носния гръб) за първи път е извършена и представена с документи и снимки от J. Roe през 1887 г. (Маджаров 1975). Тогава тя е извършена с помощта на костна ножица. Медиалната остеотомия е въведена за първи път от Weir R. през 1892 г. През 1931 г. J. Joseph усъвършенства и извършва по-щадящи латерални остеотомии, като ги извършва с помощта на малко трионче. За целта първо създава субпериостален тунел чак до корена на носа. По-късно пак той, Anderson (1974) и др. прилагат широко остеотомно длето за резекция на носния гръб. Идеята и провеждането на латералните остеотомии се преписва на J. Dieffenbach през 1845 г. Ендоназалната латерална остеотомия достига предела на своите възможности благодарение на Massing (1977). Той конструира и използва специални длета, които се използват и днес и носят неговото име. Безпорно прилагането им при латерална остеотомия е обаче все още твърде травматично. Това произтича от големия размер на длетата и начина на извършване.
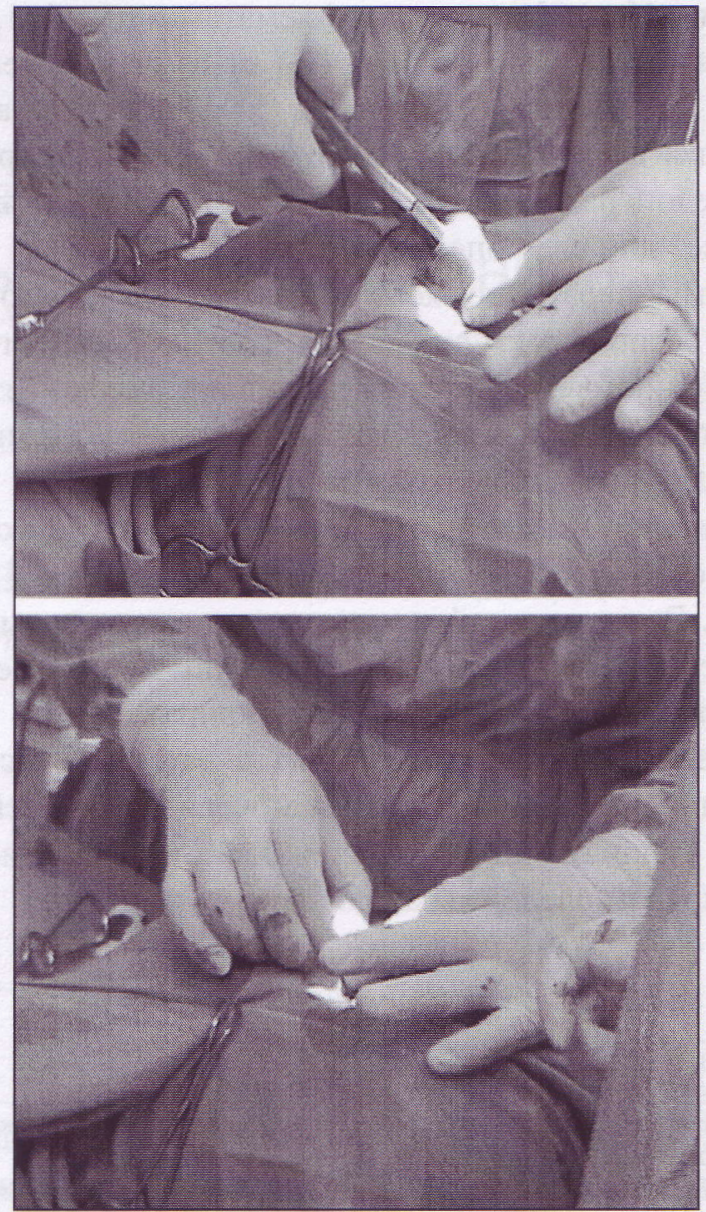

Фиг. 10. Фрактуриране с луер и дигитално наместване на фрактуририраните костни елементи

Друг недостатък е, че тя не е контролирана и опасностите да се травмират слъзните канали, слъзната торбичка, а така сыщо и орбитата е реална.

Като че ли първото описание на перкутанните остеотомии е дадено от Trendelenburg (1844 -1924). Той прави външен кожен разрез в областта на nasion и с длето се постига отделяне на носните кости от фронталните и по-пълна мобилизация на носната пирамида.

Идеята за прилагане на перкутанна остеотомия заимствахме от трудовете на Trenite (1998). Необходимостта от латерални остеотомии произтича от това, че гърбът на носа след медиалната остеотомия остава отворен. Това има за късен резултат оформяне под формата на трапец на гърба на носа - доста неприятно усложнение. Латералната остеотомия следва да се извьрши симетрично и от двете страни на носа. В случаите на костно-хрущялен крив и несиметричен от двете страни нос предприемаме съответно и несиметрични остеотомии.

След този вид остеотомии периорбитален оток и хематом сме наблюдавали само в единични слу- 
чаи - 12 (4,3\%), подкожен хематом - при $5(1,8 \%)$ и епистаксис - при $1(0,4 \%)$ от случаите, непълно фрактуриране - при 14 (5,03\%) от случаите. Болка след операция също не сме констатирали. Следоперативният видим кожен белег изчезва десет дни след операцията.

Интраоперативно констатирахме, че се постига лесно фрактуриране на костните структури. Позицията на длетото в медиална посока (извън окото, за разлика от ендоназаланата остеотомия на Masing) го прави значително по-безопасна.

Размерът на длетото - 2 мм, е предпоставка то да е по-атравматично от това на Masing - 5-6 мм. Възможно най-малка или липса на травма на носната лигавица. Контролирано постигане на желано по обем и място фрактуриране.

Предимствата на перкутанната латерална остеотомия пред ендоназалната са очевидни и безспорни. Нашият опит с тази техника ни позволява да направим следното заключение:

\section{Литература:}

1. Бенчев Р., Павлов В. Отворен подход за риносептопластика. Оториноларингология 1999; бр. 3: 14-18.

2. Деспотов О., Карчев Т., Богданов Е. Нов оперативен метод при риносептопластика. Оториноларингология 2002; бр. 3-4: 50-51.

3. Маджаров М., Корективна риносептопластика. Изд. "Филвест" София, 1997, стр. 27 -- 30

4. Anderson I., Lundqvist G.R., Jensen P.L.: Human response to controlled levels of sulfur dioxide, Arch. Environ Health., 1974, 28, 3139.

5. Daniel R.K., The nasal tip: Anatomy and aesthetics. Plast. Reconstr. Surg. 1992, 89, 216-224.

6. Despotov O. Corrective rhinoseptoplasty without lateral osteotomy Comptes rendus de l'Acade'mie bulgare des Sciences Vol 60 № 4 pp. $463-470$

\section{Заключение}

Въз основа на близо двадесетгодишен опит в областта на риносептопластиката и въз основа на литературата препорьчваме перкутанните остеотомии да бъдат предпочинани пред ендоназалните. Могат да се обобщят следните предимства на перкутанните остеотомии пред ендоназалните:

1. Те са по-атравматични;

2. Те са по-лесни за изпълнение;

3. Те са по-безопасни;

4. Позволяват контролирано и прецизно приложение;

5. Значително се съкращава постоперативният период.
7. Goodman S.W., Gilbert W.R., The anatomy of External Rhinoplasty., Otrhinolaryngologic Clinics of North America., 1987, ${ }^{14}$, vol 20, 641653.

8. Trenite Nolst G.J. RHINOPLASTY $-2^{\text {nd }}$ enlarged edition with interactive CD-ROM (Kugler Publications The Hague/The Netherlands 1998)

9. Masing H., et al. Nasal pressure flow studies in adults and children., Rhynology 1974, 12, 137-143.

10. Masing H., Functional aspects in septal plasty., Rhinology. 1977, 15, $167-172$.

11. Masing H., Chirurgie des Nasenseptums. InHals-Nasen-Ohrenheilkunde in Praxis und Klinik von J. Berendes, R. Link und F. Zolner, 1977, Band 6, 26.22-26.28 